\title{
Aerosol Filtration Testing of Fabrics for Development of Reusable Face Masks
}

Aerosol and Air Quality Research

Special Issue:

Special Issue on COVID-19 Aerosol Drivers, Impacts and Mitigation (XVII)

\section{Adrian Stan ${ }^{1 * \dagger}$, Sandro Steiner ${ }^{1+}$, Shoaib Majeed ${ }^{1+}$, Sandra Schorderet Weber ${ }^{1 \dagger}$, Samik Gosh ${ }^{2}$, Tanja Živković Semren ${ }^{1}$, Philippe Alexandre Guy ${ }^{1}$, Stefan Lebrun ${ }^{1}$, Jérôme Steinhauser ${ }^{3}$, Yanik Tardy ${ }^{3}$, Andreas Hogg ${ }^{3}$, Sophie Chiquet ${ }^{4}$, Jean-Luc Perret ${ }^{5}$, Arkadiusz Kuczaj ${ }^{1}$, Manuel Peitsch ${ }^{1}$, Julia Hoeng ${ }^{1}$}

\author{
${ }^{1}$ PMI R\&D, Philip Morris Products S.A., CH-2000 Neuchâtel, Switzerland \\ 2 SBX Technologies, Tokyo, Japan \\ ${ }^{3}$ Coat-X SA, La Chaux-de-Fonds, Switzerland \\ ${ }^{4} \mathrm{CQ}$ Corporate Fashion $\mathrm{GmbH}$, Zürich, Switzerland \\ ${ }^{5}$ INVENesis Sàrl, Neuchâtel, Switzerland
}

\section{ABSTRACT}

The ongoing outbreak of coronavirus disease of 2019 (COVID-19), triggered by the rapid community spread of the severe acute respiratory syndrome coronavirus 2 (SARS-CoV-2), has brought forward the need for speedy testing and manufacturing of respiratory face masks for global use. Overwhelmed by the fast-growing demand for disposable face masks, many governments have recommended the use of, and elaborated design criteria for, reusable face masks that are meant to slow down the transmission of SARS-CoV-2 in the general population. Using aerosol particle size spectrometers, we performed particle size distribution measurements and calculated the fractional aerosol particle size-selective filtration efficiencies of over 300 fabrics and fabricassemblies, including chiffon, cotton, synthetics, and various promising layered combinations. We suggest, and experimentally verify, a simple way for estimating the aerosol filtration efficiency of layered fabrics. The analysis herein investigates the relationship between the breathability and filtration properties of fabrics, assemblies of fabrics, and commercial reusable masks from various regions around the globe. In addition, we demonstrate how a hydrophobic coating can provide a statistically significant increase in the fabrics' filtration efficiency. The insights of this work are crucial to developing non-woven, high-filtration-performance, reusable face masks that can be worn for extended periods of time.

Keywords: Face mask, Fractional aerosol particle size-selective filtration, Pressure drop, Text mining, Hydrophobic coating

\section{INTRODUCTION}

During the coronavirus disease of 2019 (COVID-19) crisis, the persistent global shortage of personal protective equipment (PPE) has been one of the most urgent threats to curbing the unfolding pandemic. Although the availability of face masks for healthcare workers was, and still is, of prime concern, reducing the basic reproductive number $\left(R_{0}\right)$ of COVID-19 relies on the widespread implementation of measures in the general population, e.g., social distancing, the wearing of face masks, remote working. The implementation of large-scale, mandatory face mask use in public places puts an unprecedented level of pressure on an already strained supply chain for disposable face masks made of melt-blown fibers (Wu et al., 2020). In addition, as the COVID-19 pandemic unfolds, PPE items are being discarded at an unprecedented rate, creating an environmental crisis that puts an estimated $<120$ billion masks into the environment every 
month (Fadare and Okoffo, 2020; Prata et al., 2020).

Since February 2020, an increasing number of governments have mandated the use of face masks in public places. By June 2020, for example, more than 5.7 billion people (approximately $75 \%$ of the world's population) were under provisions to wear face masks in various public places, and their number only increased (Wikipedia, 2020). There has been a growing consensus in the scientific community that face masks-including self-made, do-it-yourself (DIY) cloth masksprovide an important means of breaking the exponential transmission curves and controlling the community spread of the virus (Clase et al., 2020; Eikenberry et al., 2020; Leung et al., 2020; Pleil et al., 2020; Sunjaya and Jenkins, 2020). In April 2020, scientists from the Yale School of Public Health (Abaluck et al., 2020) recommended the immediate universal adoption of cloth face masks-including washable, reusable, homemade masks - as a response to the shortage of PPE for healthcare workers. As of 5 June 2020, the World Health Organization (WHO) also advised governments to encourage the general population to use face masks to reduce the transmission of SARS-CoV-19 (severe acute respiratory syndrome coronavirus 2) (BBC News, 2020; The New York Times, 2020). Mathematical models of an influenza pandemic scenario (Tracht et al., 2010) and a COVID-19 pandemic scenario (Stutt et al., 2020) show that the use of masks at the population level significantly decreases the infection rate and helps contain the pandemic (Brienen et al., 2010).

Three important considerations are generally quoted when advising or mandating the use of face masks in the general population: 1) Medical face masks and respirators should be conserved and prioritized for use by healthcare professionals; 2 ) the use of face masks in the general population should not lead to a false sense of security, which, in turn, can lead to suboptimal social distancing, poor respiratory etiquette, and neglect of hand hygiene; and 3) improper removal and handling of face masks and an increased tendency to touch the face while wearing a face mask might increase the risk of transmission (ECDC, 2020; Federal Office of Public Health, 2020; Greenhalgh et al., 2020; Safe Communities Portugal, 2020; WHO, 2020).

Medical devices such as medical face masks can be broadly divided into two categories: medical face masks and personal respirators. The former, also termed surgical face masks, protect the surroundings of the individual from contamination in case the wearer is infected. These are regulated by different standards around the world; for example, within the European Union (EU), the standard EN 14683 classifies medical devices of this kind into three categories: Type I, Type II, and Type $I^{R}$ (European Comittee for Standardization, 2019). Personal respirators, conversely, protect the wearer in an environment where the risk of contracting a respiratory disease is high. These, too, are regulated under different standards depending on the region of the world-for example, N95, N99, and N100 in the United States (US) or FFP 1, FFP 2, and FFP 3 in the EU (NIOSH, 1996; European Comittee for Standardization, 2009). For a brief discussion on the differences between these two types of medical devices and how we used these standards in the current study, please see Supplemental Material 1.

During the initial stages of the COVID-19 pandemic, in light of a strained supply chain, a direct need to prioritize the use of medical face masks for the massive response of healthcare systems led to the rise in popularity of DIY face masks in the general population (World Economic Forum, 2020). Numerous tutorials for sewing or knitting homemade DIY face masks were disseminated in the social, local, and national media of virtually every country affected by the pandemic. Frequently, these guides were shared without clear templates or material recommendations. A study from 2013 that screened some common household fabrics found that they had significantly lower filtration efficiencies than medical face masks (Davies et al., 2013).

Several European countries have defined scientific standards for reusable, commercially made fabric face masks. For example, in France, specifications were drawn up by the General Directorate of Armaments of the Ministry of the Armed Forces (DGA, 2020). In Switzerland, the criteria regarding the materials for non-medical face masks were established by the Swiss Federal Laboratories for Materials Science and Technology (Federal Office of Public Health, 2020; NCS-TF, 2020) (see Supplemental Material 2). The European Committee for Standardization and the European Committee for Electrotechnical Standardization have made available a series of standards applying to medical equipment and PPE used to face the COVID-19 pandemic (Abaluck et al., 2020). Several countries in the Asia-Pacific region-for example, Singapore, Hong Kong, and Taiwan-have recommended the use of face masks (Wikipedia, 2020). The US Centers for Disease Control and Prevention issued a guideline for wearing cloth face masks in public settings where 
other social distancing measures are difficult to maintain (CDC, 2020). Although the criteria for reusable face masks vary regionally and nationally, in general, they are required to have some particle-filtration properties and not overly hinder breathing (MacIntyre and Hasanain, 2020). Characterization of the aforementioned properties for a wide spectrum of fabrics requires experimental determination of the pressure drop across the material and, for a given aerosol, the particle size-selective filtration properties of the material.

Aerosols are suspensions of solid or liquid particles in a carrier gas. These particulates may embed biological constituents, such as pollen, fungal spores, viruses, and bacteria. When it comes to their physical properties, aerosols are characterized by their particle size distribution (PSD), which provides information on the number density and size of the particles present therein. Changes in the recorded PSD before and after filtration can be used as a quantification tool for the filtration process, i.e., the separation of particulates from the carrying gas by various physical or chemical mechanisms (Hinds, 1999). For a brief discussion on the relevant filtration mechanisms, please see Supplemental Material 3.

The fractional filtration efficiency, $F E(d)$, expresses the percentage or fraction of particles of diameter $d$ that are retained by a filter, often derived as $1-P(d)$, from the measured fractionalpenetration $P(d)$, which represents the particle size-specific percentage (or fraction) of particles that evade filtration. The $F E(d)$ is commonly plotted across a particle size range, yielding the spectrum of filter performance. Importantly, for fixed flow conditions, assuming negligible aerosolparticle interactions during the filtration process, the fractional filtration efficiency is independent of the PSD of the aerosol and, hence, said to be a property of the filter (Schmidt, 2008; Thomas et al., 2016). The total filtration efficiency (TFE) is expressed across all particle sizes present in the aerosol, and captured by the particle sizer, and can be defined as the fraction of the particle number, particle surface area, particle volume or particle mass that is removed by a filter material from a specified volume of a given aerosol. Because it is calculated as an average, the TFE does not account for particle size-selective deficiencies of the tested filters.

In further describing the filter, the pressure drop $(\Delta P)$-also termed resistance to airflow or, in the context of face masks, breathability-is a crucial parameter. Low breathability of the material (high $\Delta P$ ) will lead to an increase in airflow via the imperfect fit of the mask (leakage) and to a sharp decrease in the efficacy of the face mask. The pressure drop increases with the thickness of the filter, fiber density, and speed of the aerosol flow. Furthermore, water condensation may change the initial filtration properties of the filter. We address the hydrophilic and hydrophobic properties of the fabrics later in this manuscript.

Among aerosols, and for the present work, of particular interest are those generated during biomechanical processes such as breathing, coughing, sneezing, and speaking. Such aerosols are the means of airborne transmission of infectious diseases, as, during these processes, viruses become enclosed in aerosol particles of sub-micrometer and super-micrometer scales (Morawska et al., 2009; Han et al., 2013; Tang et al., 2013; Jayaweera et al., 2020). Unfortunately, the distribution of biological material inside these various particle sizes remains largely unknown, and it is accordingly difficult to define the fractional filtration efficiencies that should be met by a given face mask in order to provide an acceptable level of protection. The lower limit of the relevant particle sizes is theoretically given by the size of the infectious agent expected to be present in the aerosol. In the case of SARS-CoV-2, this limit is around $0.1 \mu \mathrm{m}$ (Kim et al., 2020). Once exhaled, the dynamic of super-micron particles (the upper limit of relevant particle sizes) is likely to be influenced by gravity, whereas gravity has little impact on sub-micrometer particles. These latter particles undergo thermodynamic equilibration with the environment (i.e., condensation or evaporation processes) and may be carried over large distances by natural and forced convection (Bourouiba, 2020).

The central purpose of reusable face masks - or of surgical face masks, for that matter-is to mitigate the risk of the wearer spreading a contaminated aerosol in the environment through breathing, coughing, sneezing, or speaking. Conversely, personal respirators such as N95 are intended to protect the wearer in highly contaminated environments, performing, in a sense, the opposite function to that of surgical face masks. While, in the latter, protection of the wearer from environmental contaminants can only be a desirable side effect, there is evidence that surgical face masks are effective at protecting the wearer from infections such as influenza (Long et al., 2020). In this context, the inward-leakage measurement-referred to as the fit factor, i.e., 
the ratio of the concentration of gas or aerosol in the environment to that inside the face maskis an important measure of the efficacy of personal respirators (see also the discussion in Supplemental Material 2 and the references therein).

Even before the COVID-19 pandemic, the scientific community was conducting studies aimed at determining the filtration efficiencies of various household items. van der Sande et al. (2008) demonstrated that face masks made of tea-towel cloth may confer a certain degree of protection against influenza, albeit far from that offered by disposable face masks or FFP2 personal respirators. It was also shown that single-layer household fabrics made of linen, silk, or vacuum cleaner bags provided some protection from microorganisms in filtration experiments with highconcentration bacterial and viral aerosols (Davies et al., 2013). In another study, single layers of common household fabrics tested for filtration of nano-sized particles provided only marginal respiratory protection (Rengasamy et al., 2010). A study conducted in 2015 in a healthcare setting indicated that face masks made of two layers of cotton had a far lower filtration capacity than medical face masks; the study hypothesized that, because of the higher moisture retention of cotton face masks, their use may increase the risk of autoinfection (Maclntyre et al., 2015).

Research conducted in the context of the COVID-19 pandemic, and aimed at determining filtration efficiencies as a function of aerosol particle size, has shown that assemblies of multiple layers of fabrics, e.g., cotton-silk, cotton-chiffon, cotton-flannel, can achieve filtration efficiencies of $>80 \%$ for particles $<300 \mathrm{~nm}$ and $>90 \%$ for particles $>300 \mathrm{~nm}$ in size (Konda et al., 2020). Some more efficient designs comprising hydrophilic absorbent layers (e.g., tea towel, quilting cotton, and flannel) combined with hydrophobic barriers (e.g., polypropylene, polyester, and polyamide) have also been described in the literature (Lustig et al., 2020). Further, some authors have attempted to determine if filtration enhancement can occur following charge deposition on household fabrics (Zhao et al., 2020). The particle filtration efficiency of triple-layer cotton face masks compared with medical face masks has recently been investigated (Ho et al., 2020). Adult volunteers with confirmed influenza or suspected COVID-19 infection were asked to wear either a medical face mask or a DIY triple-layer cotton face mask in a confined environment, such as a bedroom or car. The authors did not find a significant difference between the performance of these face masks, neither in the number of 20 - to $1000-\mathrm{nm}$ particles released by the volunteers during $1 \mathrm{~h}$ of constant measurement nor in the cough versus sneeze counts.

The present work of the ProMask.CH consortium aims at protecting public health by providing insights into the filtration properties of non-woven fabrics that are also fashionable enough to encourage the wide adoption of face masks in the general population. To this end, we used semiautomated text mining to build a compendium of fabrics employed across the world to fabricate face masks, and we investigated the filtration properties and breathability of more than 300 such fabrics. In addition, we have evaluated a set of recently designed, commercially available, reusable face masks from various regions of the world, determined their fractional filtration properties and breathability, and compared these to national and regional requirements. Finally, we explored the effects of a biocompatible hydrophobic coating on a subset of fabrics and show its relationship to filtration properties.

\section{METHODS}

\subsection{Building a Compendium of Fabrics Used across the Globe}

We employed a semi-automated text-mining platform, powered by Taxila ${ }^{\mathrm{TM}}$ (SBX, Tokyo, Japan), to conduct a systematic, global search for information streams describing fabrics and patterns used to make DIY face masks (Fig. 1). With text mining, data aggregation, visualization, and reporting, the platform dynamically collected information from various public-domain sources, such as blogs, governmental platforms, publications, and published reports, on a daily basis.

Over 1500 key information sources from various regions, particularly Asia, where the virus first spread, were amassed on the above-mentioned dimensions. A dynamic dashboard was constructed by gathering the information sources and the automated mined content, generating visualizations and reports to identify key face mask protocols and materials. On the basis of the Taxila ${ }^{\mathrm{TM}}$ selection, the first materials considered were a set of household items that were surprisingly close to those examined by van der Sande et al. (2008) and Davies et al. (2013). The data collected revealed 
that the majority of solutions proposed around the world were similar, and we subsequently expanded our search to easily accessible commercial materials.

During the screening process (see the Results section), and supported by the results put forward by Taxila ${ }^{\mathrm{TM}}$, we considered combinations of layered fabrics that we termed "Assemblies". Shown schematically in Fig. 2, these were tested in accordance with the same procedure as that used for single materials, with the layers being measured in one orientation of the fibers only.

\section{Data Aggregation}

\section{Analytics and Mining}

\section{Visualizations and Reports}

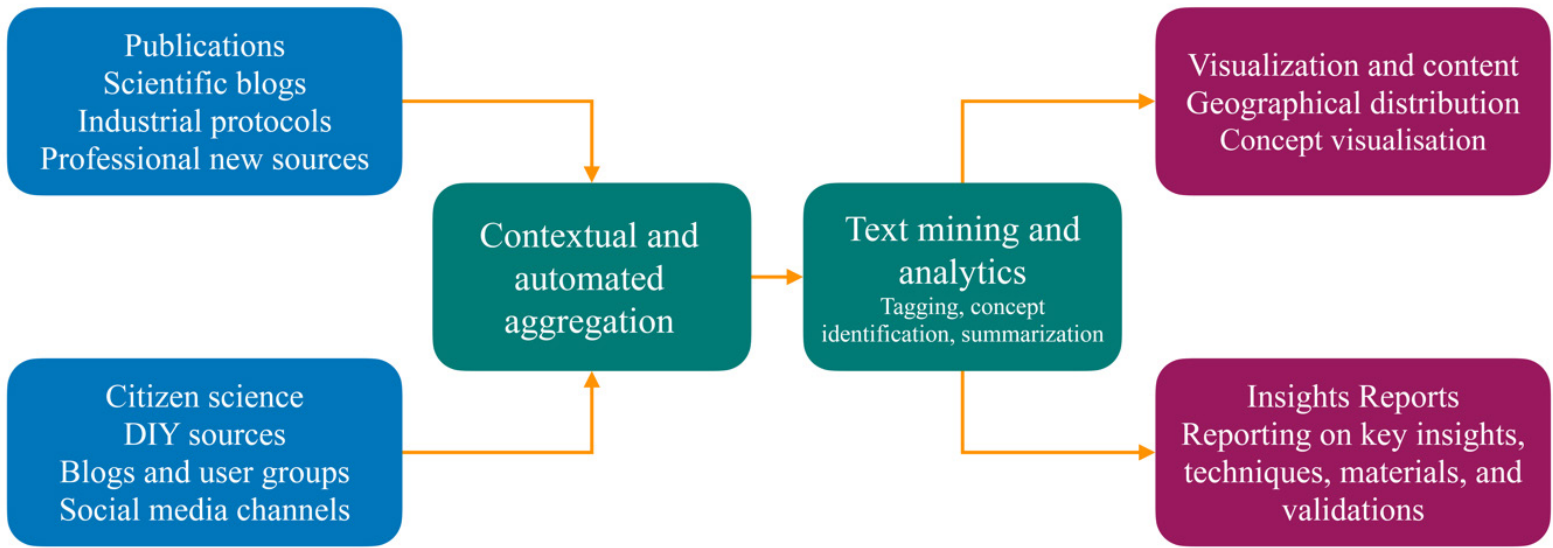

Fig. 1. The Taxila ${ }^{\mathrm{TM}}$ workflow used in this work. Taxila ${ }^{\mathrm{TM}}$ is a knowledge aggregation and mining platform for both text and data. It leverages natural language processing combined with contextual search, aggregation, and text analysis to identify actionable insights.

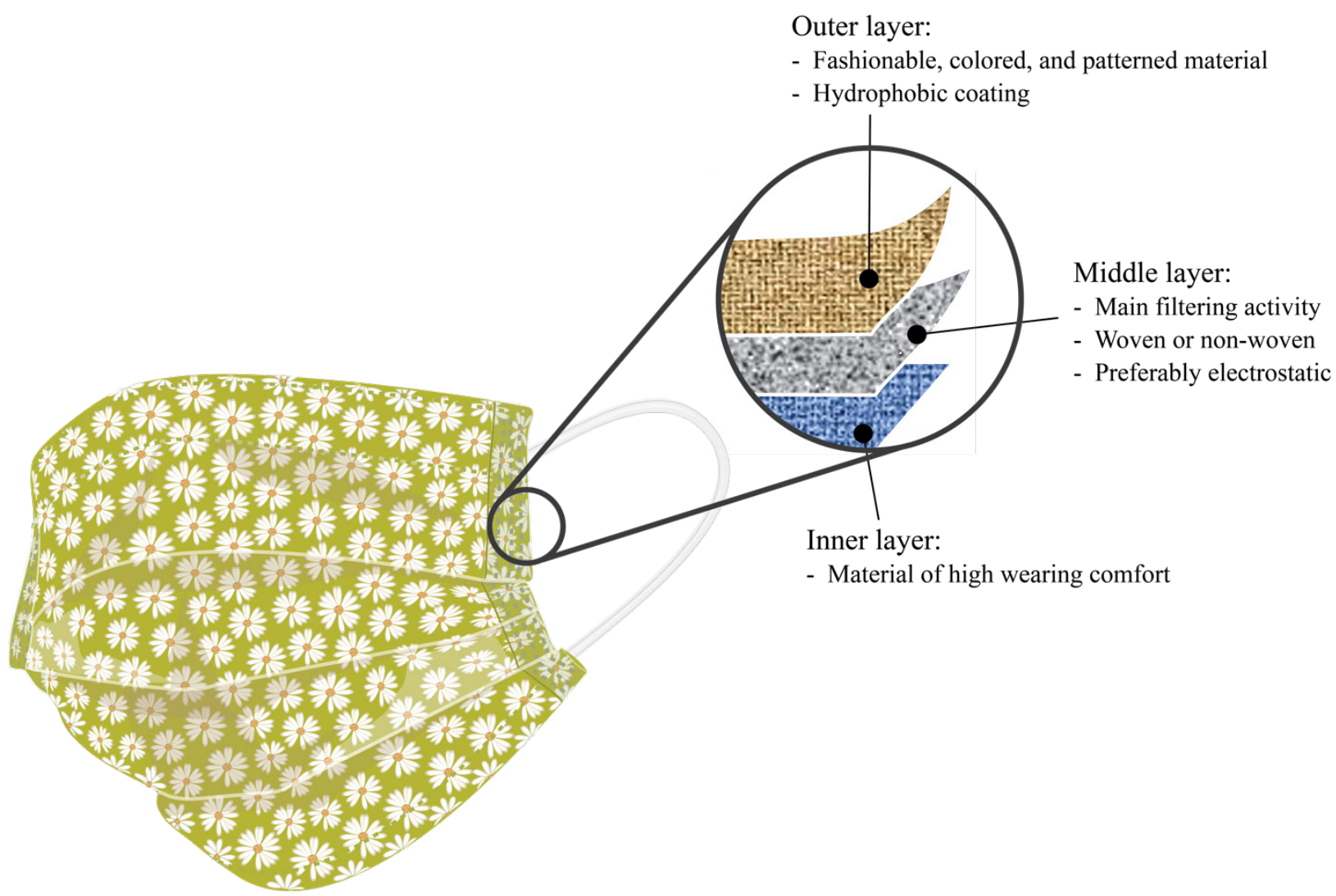

Fig. 2. The basic scheme of an Assembly obtained by combining several materials with various filtration efficiencies across the particle size range, different pressure drops, and different look and feel. 


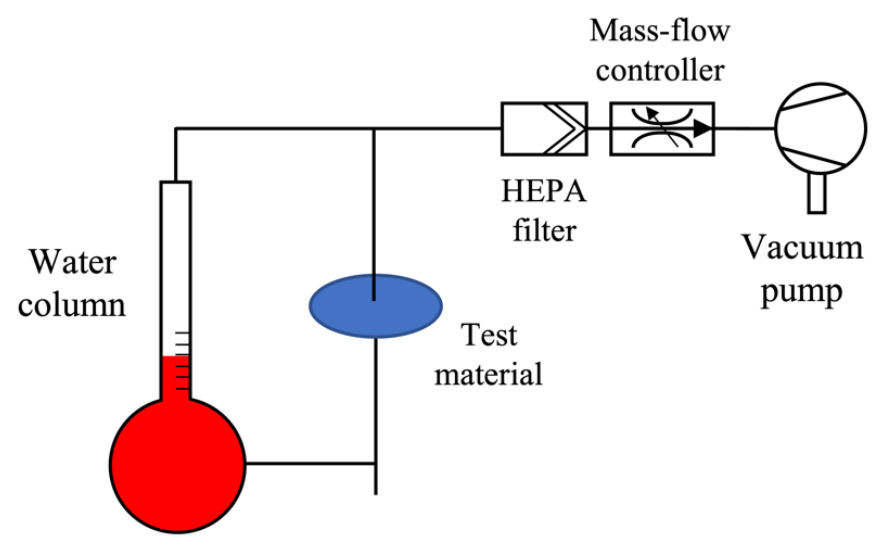

Fig. 3. Water column-based experimental setup used for measuring pressure drop across the samples. A HEPA filter was added to protect the mass-flow controller (Analyt MTC Messtechnik $\mathrm{GmbH}$, Müllheim, Germany, Model \# 35831) and vacuum pump. The circular patches of test material were clamped into the aerosol flow.

We also investigated several non-medical, reusable face masks currently on the market. With one exception, and to the best of our knowledge, all these face masks have appeared in the context of the COVID-19 crisis. Geographically, roughly one-third of these products come from Asia-i.e., Republic of India, People's Republic of China, The Socialist Republic of Vietnam, and Hong Kong Special Administrative Region of the People's Republic of China, and roughly two-thirds from Continental Europe, including the French Republic, Italian Republic, Portuguese Republic, and the Swiss Confederation. In all cases, the description of the product claimed a certain efficiency against respiratory diseases, if not a direct claim of efficiency against SARS-CoV-2.

\subsection{Pressure Drop Measurements}

The pressure drop across circular patches $\left(r=1.9 \times 10^{-2} \mathrm{~m}\right)$ of test materials was measured by using the equipment shown schematically in Fig. 3. The system was set in operation and allowed to equilibrate, and the height of the water column formed in the absence of any test material, i.e., the background originating from the systems' flow resistance, was measured. The test material was clamped into the holder and the height of the water column measured again. The net pressure difference across the test material was obtained by subtracting the background and converting to Pascal ( $\mathrm{Pa}$ ). Measurements were conducted in single repetition during the screening and selection stage of this work and in five independent repetitions for the data presented and discussed here.

\subsection{Aerosol Filtration Efficiency Testing}

Fig. 4 shows the experimental setups employed for determining the filtration properties of all samples considered in this work. For characterizing these filtration properties, two types of aerosols were used:

a. a liquid-particle aerosol consisting of propylene glycol (PG), glycerol (G), and phosphatebuffered saline (PBS) - referred to as "PG/G aerosol" (PG: Sigma Aldrich, Buchs, Switzerland, Ref \#82280, G: Ref \#G9012, PBS: \#D8537)

b. a dry, sodium chloride particle aerosol - referred to as "NaCl aerosol" ( $\mathrm{NaCl}$ : Sigma Aldrich, Ref \#S9625).

The rationale behind using two distinct aerosols is as follows: Because an $\mathrm{NaCl}$ aerosol is more monodisperse and has a sub-micrometer mean particle size, we used it for the large, initial screening of the fabrics. In doing so, we followed an assumption often made during the development of occupational health filters for aerosols: Screening in the vicinity of the most-penetrating particle size (MPPS) area constitutes a good selection criterion for a filter that is to be further explored with a liquid aerosol. For this latter purpose, we used a more polydisperse PG/G aerosol that, with a selected matrix composition, yields an aerosol with a stable PSD and properties similar to those of the virus-carrying particles that result from human speech, sneezing, or coughing (Bourouiba et al., 2014; Jayaweera et al., 2020). We determined the aerosol size-selective filtration 

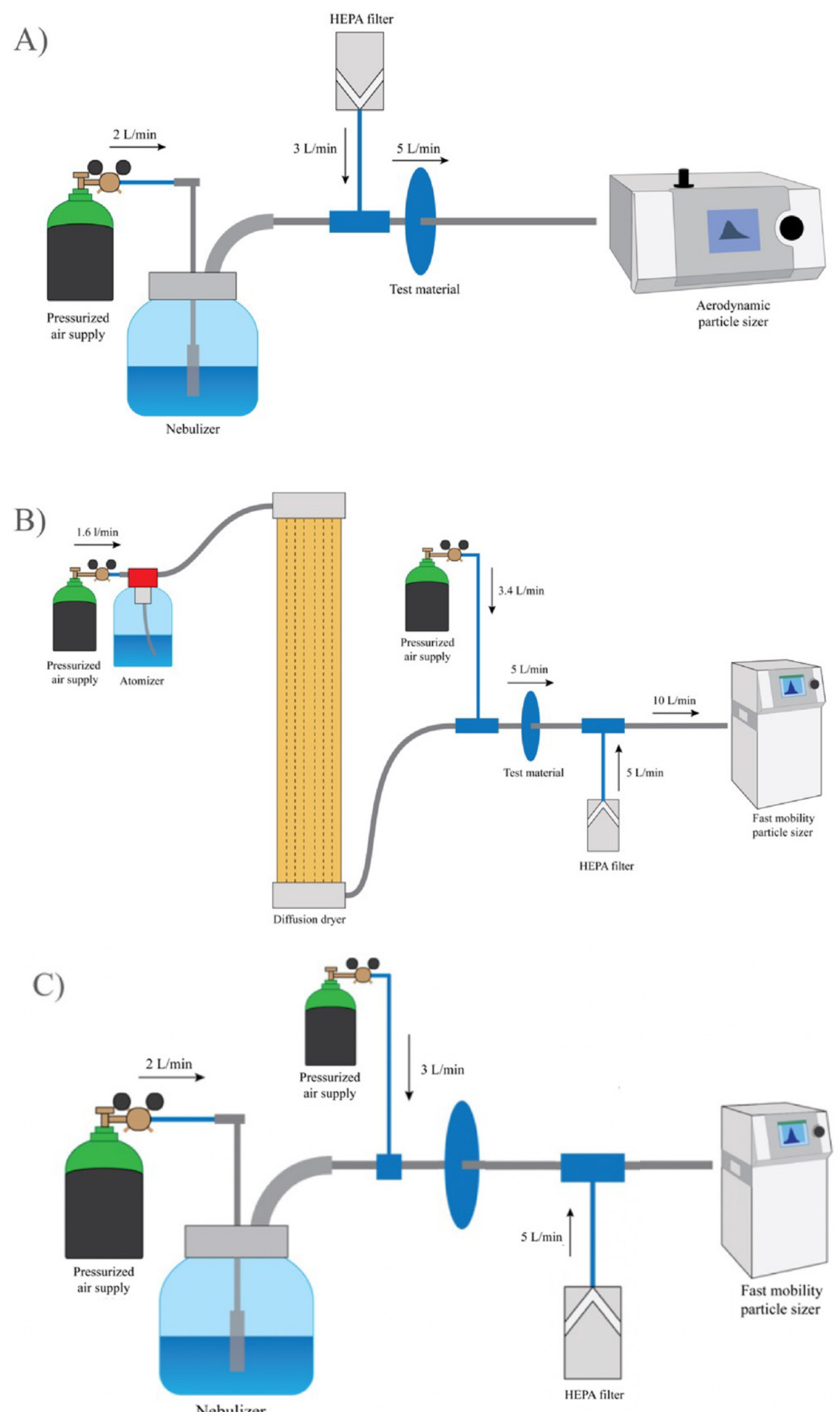

Fig. 4. Sketches of the experimental setups used for measuring filtration efficiencies. Distinct aerosol particle size ranges were measured with an aerodynamic particle sizer (APS) and a fast mobility particle sizer (FMPS). (A) and (C): measurement of PG/G particle filtration using the APS or the FMPS respectively. (B): measurement of $\mathrm{NaCl}$ particle filtration using FMPS. 
properties of the fabrics by performing measurements of the PSD of the aerosol before and after filtration. Particle size measurements ranging from nanometer to super-micron dimensions required the use of two different size spectrometers (see below) that operate on different principles and flow conditions, thereby introducing unavoidable but tolerable bias.

The PG/G aerosol was generated by operating, at room temperature, a single-jet Collison nebulizer from $\mathrm{CH}$ Technologies, Westwood, USA. The nebulized liquid matrix was composed of $57 \%$ PG $27 \%$ G, and $21 \%$ phosphate-buffered saline and was changed every 30-60 min (Iskandar et al., 2016). The flow rate entering the nebulizer was set to $2.0 \mathrm{~L} \mathrm{~min}^{-1}$. NaCl aerosols were generated with a $2 \%$ solution of $\mathrm{NaCl}$ and distilled water, passed through an ATM 226 atomizer (TOPAS GmbH, Dresden, Germany) at a flow rate of $1.6 \mathrm{~L} \mathrm{~min}^{-1}$. Water was removed from the aerosol by guiding it through a $0.45-\mathrm{m}$ diffusion dryer containing $1 \mathrm{~kg}$ of silica gel (Sigma-Aldrich St. Louis, USA).

The filtration of the PG/G aerosol was measured with a TSI 3321 Aerodynamic Particle Sizer (APS, TSI Inc., Shoreview, MN, USA) equipped with a TSI 3302 A diluter (100-fold dilution capillary) and with a TSI 3091 Fast Mobility Particle Sizer (FMPS, TSI Inc., Shoreview, MN, USA). While the APS provides aerodynamic diameter, the FMPS provides the (electrical) mobility diameter. The filtration of the $\mathrm{NaCl}$ aerosol was measured by using the FMPS, and the resulting data are shown in Supplemental Material 4. As mentioned above, the $\mathrm{NaCl}$ aerosol was used for the screening part of this project. For the PG/G aerosol, the measurements were performed with the APS and FMPS operating at a sampling frequency of $1.0 \mathrm{~s}$, and at least 15 continuous samples were collected per experimental repetition. All materials were tested in five independent repetitions, and the values obtained per test material, per repetition, were averaged. The lower and upper cutoffs of the measuring devices were: $5.6 \mathrm{~nm}$ and $523 \mathrm{~nm}$ for the FMPS and $523 \mathrm{~nm}$ and $20 \mu \mathrm{m}$ for the APS, respectively. In the following, PSD data generated with the FMPS are termed " $<0.5 \mu \mathrm{m}$ ", and those generated with the APS are termed " $>0.5 \mu \mathrm{m}$ ".

The European standard EN149 (as discussed in Supplemental Material 2) specifies the experimental setup and conditions for determining the filtration efficiency of respiratory protective devices of categories FFP1, FFP2, and FFP3 and sets the total volume flow rate through the sample at $95 \mathrm{~L} \mathrm{~min}^{-1}\left(9.5 \times 10^{-2} \mathrm{~m}^{3} \mathrm{~min}^{-1}\right)$. We followed these recommendations for testing the materials. As the shape of an FFP dome can be approximated with a hemisphere of radius $\mathrm{r}_{\mathrm{HS}}=$ $0.05 \mathrm{~m}$, resulting in a surface area $A_{H S}=3 \times 10^{-2} \mathrm{~m}^{2}$, the corresponding total volume flow rate per area is $0.32 \mathrm{~L} \mathrm{~min}^{-1} \mathrm{~cm}^{-2}$. As both $\Delta P$ and filtration efficiency depend on the flow velocity (and, therefore, at fixed volume flow rates, on filter area), they were always measured at this areaspecific volume flow rate in order to be aligned with EN 149.

The experimental setups used for measuring filtration are shown schematically in Fig. 4 . The aerosol filtration efficiencies of the test materials were measured by using patches with a radius of $2.2 \times 10^{-2} \mathrm{~m}$. The area-specific flow rate of $0.32 \mathrm{~L} \mathrm{~min}^{-1} \mathrm{~cm}^{-2}$, calculated on the basis of EN 149, entailed an aerosol flow rate of $5 \mathrm{~L} \mathrm{~min}^{-1}$ through the sample. In the APS, the required flow rate of $5 \mathrm{~L} \mathrm{~min}^{-1}$ called for an open Y-piece to be installed upstream of the material holder. The FMPS actively generates a flow rate of $10.0 \mathrm{~L} \mathrm{~min}^{-1}$. Achieving a total flow of $5.0 \mathrm{~L} \mathrm{~min}^{-1}$ through the test material necessitated the addition of an air volume of $3.0 \mathrm{~L} \mathrm{~min}^{-1}$ for the $P G / G$ aerosol and $3.4 \mathrm{~L} \mathrm{~min}^{-1}$ for the $\mathrm{NaCl}$ aerosol directly after the aerosol generators as well as the installation of an open Y-piece between the test material and FMPS for another $5.0 \mathrm{~L} \mathrm{~min}^{-1}$ of flow to be taken up (see Fig. 4).

We point out here that, insofar as the norms for testing disposable face masks, neither the EN 149 nor the EN 14683 norm, for example, require an aerosol neutralization component in the experimental setup. However, it is important to show to what extent the electrostatic filtration plays a role across the filtration efficiency spectrum of disposable and reusable face masks.

To test for the possible effects of aerosol charge, we used a TSI Advanced Aerosol Neutralizer Model 3088 that was inserted between the aerosol source and the tested filter material, with the rest of the experimental setup being identical to what is shown in Fig. 4(A) (only the PG/G aerosol was tested). This neutralizer model uses a low-energy $(<9.5 \mathrm{keV})$ soft $X$-ray source to generate high concentrations of ions with positive and negative polarity. Further, the device ensures sufficient residence time to effectively induce a steady-state charge distribution on the incoming aerosol. A total of 22 separate fabrics were chosen randomly from the set off all fabrics available to us at the end of the study. In addition, 4 different models of surgical masks were tested in the new setup. 
The aerosol mass concentrations were in the range of $200 \mathrm{mg} \mathrm{m}^{-3}$ and below, for both aerosols. The flow of $5 \mathrm{~L} \mathrm{~min}^{-1}$ was applied during no more than 60 seconds per measurement. Assuming a filtration efficiency of $100 \%$, this would result in approximately $1 \mathrm{mg}$ of trapped aerosol in total, or less than $0.1 \mathrm{mg} \mathrm{cm}^{-2}$. Repeated measurements were not conducted at the same location of the materials, i.e., only clean materials were tested. For these reasons we rule out any impact of filter loading.

From the recorded PSD, the fractional particle penetration rates were derived and converted to fractional filtration efficiencies and presented as percentages. Because the background of the instrument in the presence of aerosol, and that of the environment, were typically below $1 \%$ of the signal, further data corrections were not performed. For the material screening and selection phase of the project, the PSDs of each aerosol-sample pair were measured in one repetition only ( $\mathrm{NaCl}$ aerosol). For the PG/G aerosol data, the PSDs of each aerosol-sample pair were measured in five repetitions.

It is worth mentioning that the results obtained by particle sizers that relay on different physical principles (such as: time of flight vs. electrical mobility) cannot necessarily be compared to each other on a one-to-one-basis. When measuring the PSD below $560 \mathrm{~nm}$ with the FMPS, and the PSD above $540 \mathrm{~nm}$ with the APS, a certain discontinuity in the combined PSDs is expected. However, this discontinuity should largely disappear when the data is converted to fractional filtration efficiencies. In fact, as we will later see in Fig. 5, in many instances, we obtained higher filtration efficiencies for the highest size bin measured by the FMPS than for the lowest size bin measured by the APS. We attribute this effect to the coincidence function the APS employs, i.e., with increasing the particle-concentration in the measured aerosol, the APS tends to increasingly underestimate the particle numbers per bin.

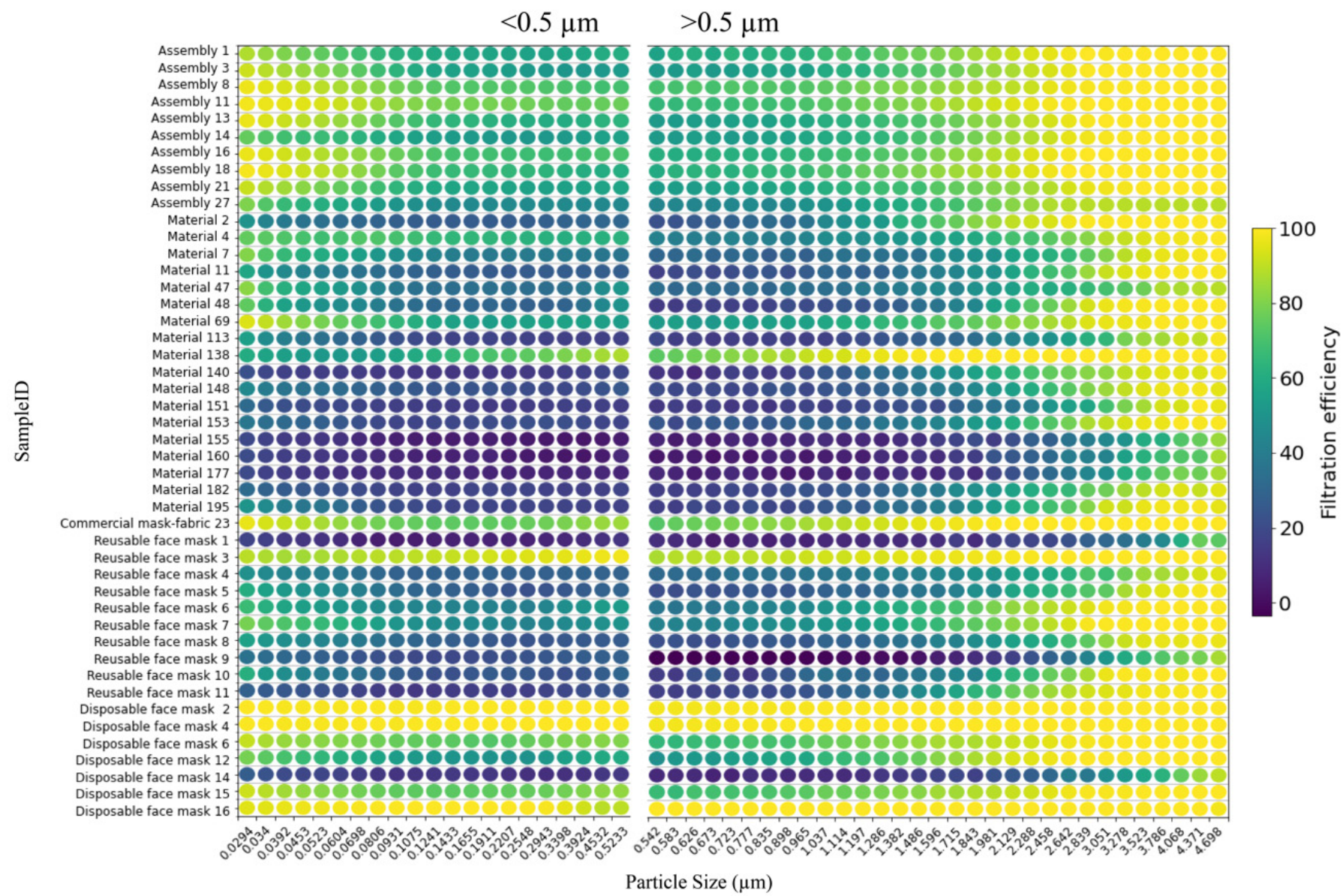

Fig. 5. Aerosol particle size-selective filtration efficiency heatmap of a subset of all screened samples identified by Sample ID. The filtration efficiency (percentage) per particle size is color-coded according to the legend. 
On the other hand, the FMPS requires an additional dilution step downstream of the test material, whereas the APS does not (see Fig. 4). We expected this to result in particle shrinkage due to evaporation, i.e., in a shift of the entire PSD towards smaller particle sizes. The evaporation in the filtered aerosol can be expected be more pronounced than in the non-filtered aerosol as the water saturation of the gas phase is lower. In addition, the filtered aerosol would be depleted of particles larger than the upper cutoff of the FMPS, as the filtration efficiency of most tested fabrics increases gradually in the upper size range. The sequence of filtration and evaporation will likely result in a disproportional depletion of particles of $500 \mathrm{~nm}$ and above, in the filtered aerosol, and hence lead to an over-estimation of the filtration efficiency in this size range.

\subsection{Theoretical Estimation of the Filtration Efficiency of the Assemblies}

When the aim is to determine the best assemblies of two or more fabrics, it is important to have a theoretical estimation of the filtration efficiency that can be reached. If potential particle interactions are neglected, the size-selective $F E(d)$ of a material is a measure that is independent of the PSD (Hinds, 1999; Thomas et al., 2016). For this reason, the collection of particles in any material of the assembly is, to a large extent, independent of the presence of other materials upstream, and the overall filtration efficiency of the assembly can be estimated by multiplying the penetration rates of each single layer of the assembly and converting the obtained product to a filtration efficiency by subtracting it from one. This can be expressed as

$F E(d)_{\exp }=1-\prod_{i=1}^{n}\left(1-F E(d)_{i}\right)$

where $F E(d)_{\text {exp }}$ is the filtration efficiency expected at particle size $d$ for an assembly consisting of $n$ layers of fabrics, and $F E(d)_{i}$ is the filtration efficiency of the $i^{\text {th }}$ layer at particle size $d$. As we were interested in commonly available materials that are not specifically designed for aerosol filtration and we used particles with negligible electrical charge, we have not considered here the aerosol filtration by electric forces. Any discussions on the charged particles, charge distribution, and electret media are outside the scope of this work.

\subsection{Contact Angle Measurements}

The hydrophobicity of fabrics was evaluated by measuring the contact angles of water droplets by using the sessile drop method. Briefly, a $0.02-\mathrm{m} \times 0.02-\mathrm{m}$ piece of material was placed on a clean, horizontal, flat support between a camera (HD Digiton Camera, Shenzhen Kayeton Technology Co, Shenzhen, China) and a bright screen diffusing a white matt light produced by a cold light source (Leica CLS 100x, Leica Microsystems, Switzerland). The camera focus was adjusted by using the internal image-capture software of the operating system Ubuntu (https://ubuntu.com/). A drop of $30 \mu \mathrm{L}$ of Nanopure ${ }^{\mathrm{TM}}$ (Thermo Fisher Scientific, Waltham, USA) water was deposited on the material to be tested, and the sharpness, contrast, brightness, zoom, and resolution of the image were optimized before taking the picture. The images were analyzed by using the open-source image processing software ImageJ (http://imagej.nih.gov/ij/download/) and the plugin "Drop Snake" (http://bigwww.epfl.ch/demo/dropanalysis/), which allowed manual measurement of the contact angles (Stalder et al., 2006).

\subsection{Hydrophobic Coating}

The filtration efficiency and comfort of a mask decrease drastically with increasing accumulated moisture from breath, saliva, and atmospheric humidity. In addition, in the context of the COVID-19 crisis, some governments have defined standards for reusable face masks; for example, in Switzerland, they are required to pass a "splash-resistance test", in which there should be no penetration of liquid (EN 14683: 2019 + AC: 2019/ISO 22609:2004; (International Organization for Standardization, 2004; European Comittee for Standardization, 2019). This is a test normally reserved for Type $I^{R}$ medical devices that are to be used by surgeons inside the operating room (see Supplemental Material 2). For these reasons, the quality and comfort of reusable face masks could be improved if the outside layer of the mask (and/or an eventual filter) were to be coated with a water-repellent thin film. 
A 250-nm coating was applied by Coat-X (Neuchâtel, Switzerland) at a pressure of 1.0 mbar, temperature of $25-35^{\circ} \mathrm{C}$, and relative humidity of $0 \%$, by chemical vapor deposition by using the deposition coating system CX1. The thickness of the film was measured with a stylus profilometer (Alpha-Step 500, Tencor, Milpitas, USA) and a reference microscope glass slide. Owing to direct solid formation from the gas phase, the deposition has a high three-dimensional conformity at a nanometer scale (Hogg et al., 2013). In consideration of eco-friendliness, compatibility, and resistance against mechanical abrasion, e.g., washing cycles, we chose a fluorine-free ceramic coating for the investigations.

\section{RESULTS AND DISCUSSION}

In the wake of the COVID-19 pandemic, the present work sought to establish a robust workflow for testing fabrics and provide an overarching picture of their properties in the context of various standards imposed by governments and regulatory bodies. We screened over 300 fabrics and assemblies of fabrics (see Supplemental Material 4). To consider as many samples as possible, after having had ensured that the standard deviation of the typical measurement was small enough, we employed a single measurement for screening the large number of fabrics tested in this study. This is an important difference to the results presented in the body of the manuscript, which are based on quintuplicate measurements. We note here that many of the fabrics we tested were found at home or were for personal use, while a subset of the materials was newly acquired (see Supplemental Material 5 for several examples). The subsets of assemblies and single fabrics considered herein were selected randomly. For assessment and comparison, we added some commercial reusable face masks available to us and a selection of disposable face masks, such as a medical Type II face mask and a generic FFP1face mask.

The heatmap in Fig. 5 summarizes the particle size-selective fractional filtration efficiencies of 18 materials (single fabrics), 10 assemblies (combinations of two or more fabrics), 10 reusable face masks (commercial reusable face masks), 7 disposable face masks (disposable face masks such as the FFP1 or Type I medical mask, which we used as benchmarks), and 1 commercial mask fabric (a fabric to be used in manufacturing a reusable face mask) (Federal Office of Public Health, 2020). Although we observed some variation among the surgical face masks that we grouped under the disposable face mask category, most of them performed in accordance with the specified standards. It is clear that most of the single materials do not have a high enough filtration efficiency in the particle size range of 0.1-1.5 $\mu \mathrm{m}$ and are, in general, poor candidates for a single-layer face mask if required for filtering particles much smaller than $3 \mu \mathrm{m}$. Assemblies of multiple fabrics commonly have a considerably higher fractional filtration efficiency in this particle size range, and the same holds true for the disposable face masks. With the notable exception of Commercial mask 3, the commercially available reusable face masks that we tested had only marginally improved filtration efficiencies compared with single materials. For additional observations on the samples considered in this manuscript, please see Supplemental Material 6.

\subsection{Aerosol Neutralization}

In the case of fabrics (see Fig. 6) when using non-neutralized versus neutralized aerosol and for sub-micrometer particles, the maximum relative difference between the two averages over measurements is of $26.4 \%$. While in absolute terms this loss in filtration efficiency is of only $3.4 \%$, this significant relative drop in filtration efficiency shows that even for woven fabrics the electrostatic filtration, at small particle sizes, plays an important role.

On the other hand, in the case of surgical masks, for the same sub-micrometer particles, the maximum difference between the two averages that involve non-neutralized versus neutralized aerosol measurements was of $8.9 \%$. Here, the loss in relative filtration efficiency is much smaller while the loss in absolute filtration efficiency stands at $7.4 \%$, larger than that for woven fabrics.

For both woven and non-woven fabrics, neutralizing the aerosol decreases, on average, the filtration efficiency of the fabric. This effect is present for sub-micrometer particle sizes, falls off slower and more uniformly for non-woven fabrics. 


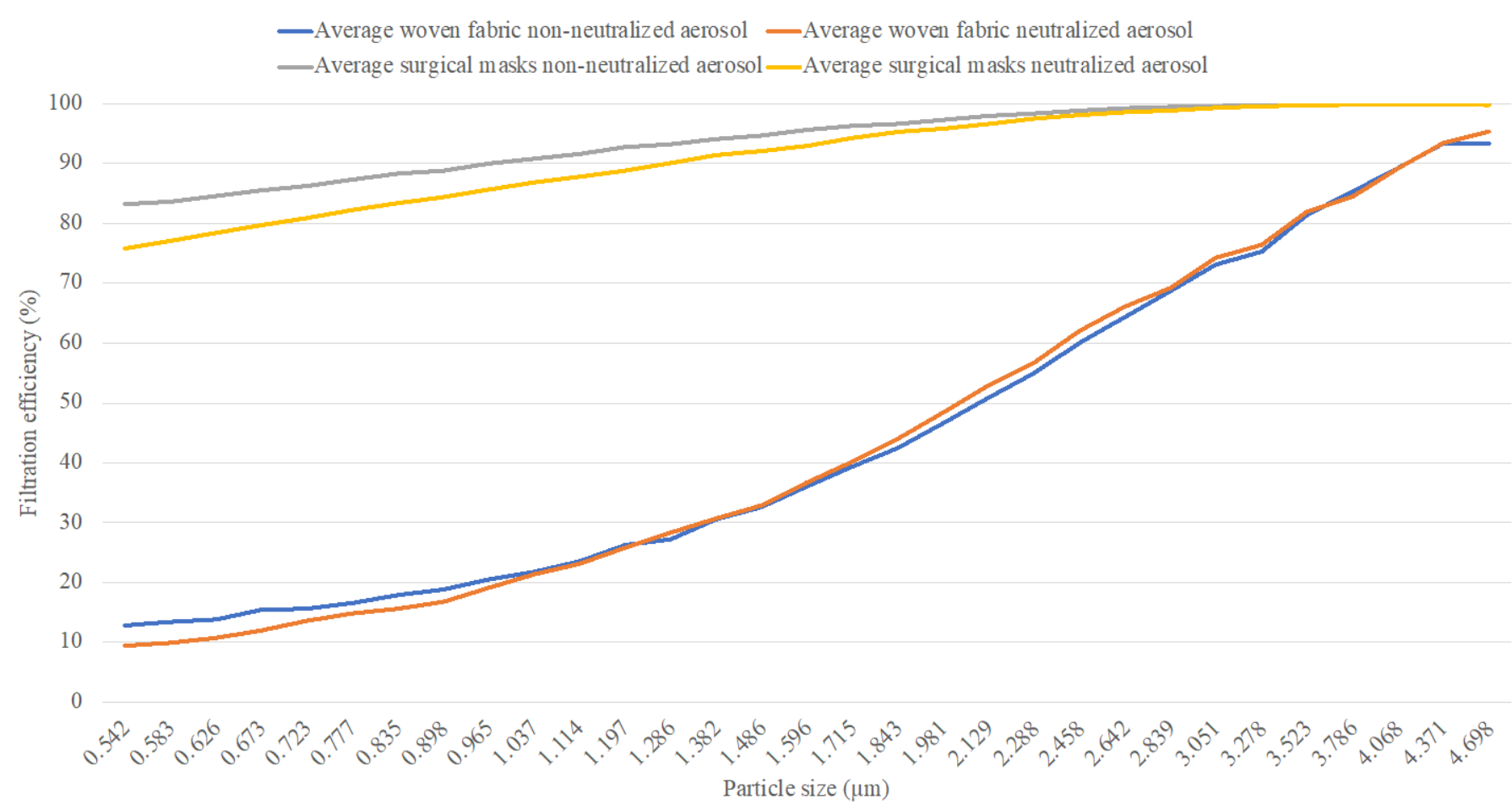

Fig. 6. Neutralized versus non-neutralized aerosol measurements of the filtration efficiency of surgical masks and woven fabrics. The curves show the average filtration efficiency over 22 woven fabrics and 4 surgical masks from different manufacturers.

\subsection{Fabric Assemblies}

We have seen that, for the materials we considered, the pressure-drop increases with the TFE, as shown by the significant correlation between the two variables, i.e., the best materials in terms of filtration efficiency also have a high pressure drop, as can be explained by the increase in their fiber-packing density. As the tight fitting of a face mask plays an equally important role as its filtration capability, it is preferable to have a high filtration efficiency without a corresponding increase in the pressure drop across the material, which would decrease breathability. Driven by these observations, we aimed to keep the breathability below the limit of $60 \mathrm{~Pa}$ (NCS-TF, 2020) and stacked layers of individual materials to form assemblies. Combining materials in the design of a reusable face mask offers the additional advantage of greater esthetic flexibility.

In total, we screened approximately 60 assemblies and, in the present work, we include 10 of these, which we subsequently measured in quintuplicate (see Supplemental Material 4). As shown in Fig. 7, the contribution of the individual materials to the TFE of the assembly is, in general, uneven, across the particle size spectrum (for example, see Assemblies 16 and 27 in Fig. 7). This means that both the total and fractional filtration efficiencies of an assembly can be tuned by the choice of materials. However, the number of possible combinations grows rapidly with the number of materials considered, and it would be of practical importance to have a computational scheme for identifying potential assemblies. We discuss this point next.

We have shown how the filtration efficiency that can be reached by combining different fabrics can be estimated. We also pointed out before that the particle size-dependent fractional filtration efficiency of a material is neither affected by the particle number density nor dependent on the initially tested PSD of the aerosol. For this reason, for the assembly, the filtration efficiency expected at particle size $d$ can be estimated by multiplying the penetration rates of the $i^{\text {th }}$ layer and subtracting the result from one. The filtration efficiency is normalized against the initial PSD, under the assumption of negligible aerosol aging (evolution) when passing through thin filtration layers. In Fig. 7, we show the measured fractional filtration efficiencies of the separated materials and the final assembly. By applying Eq. 1, we obtain the predicted fractional filtration efficiencies shown in Fig. 8. The accuracy is higher for particles $>0.5 \mu \mathrm{m}$ than for particles $<0.5 \mu \mathrm{m}$. Although the overall shape of the spectrum of particles $<0.5 \mu \mathrm{m}$ is well predicted, the values tend to 
deviate by $<10 \%$ from the experimental values. To quantify the accuracy of the model, we ran a regression analysis. The results for the two assemblies shown in Fig. 8 are shown in Fig. 9. Indeed, the $R^{2}$ values are higher for larger particles, although the differences do not seem to stray from linearity.
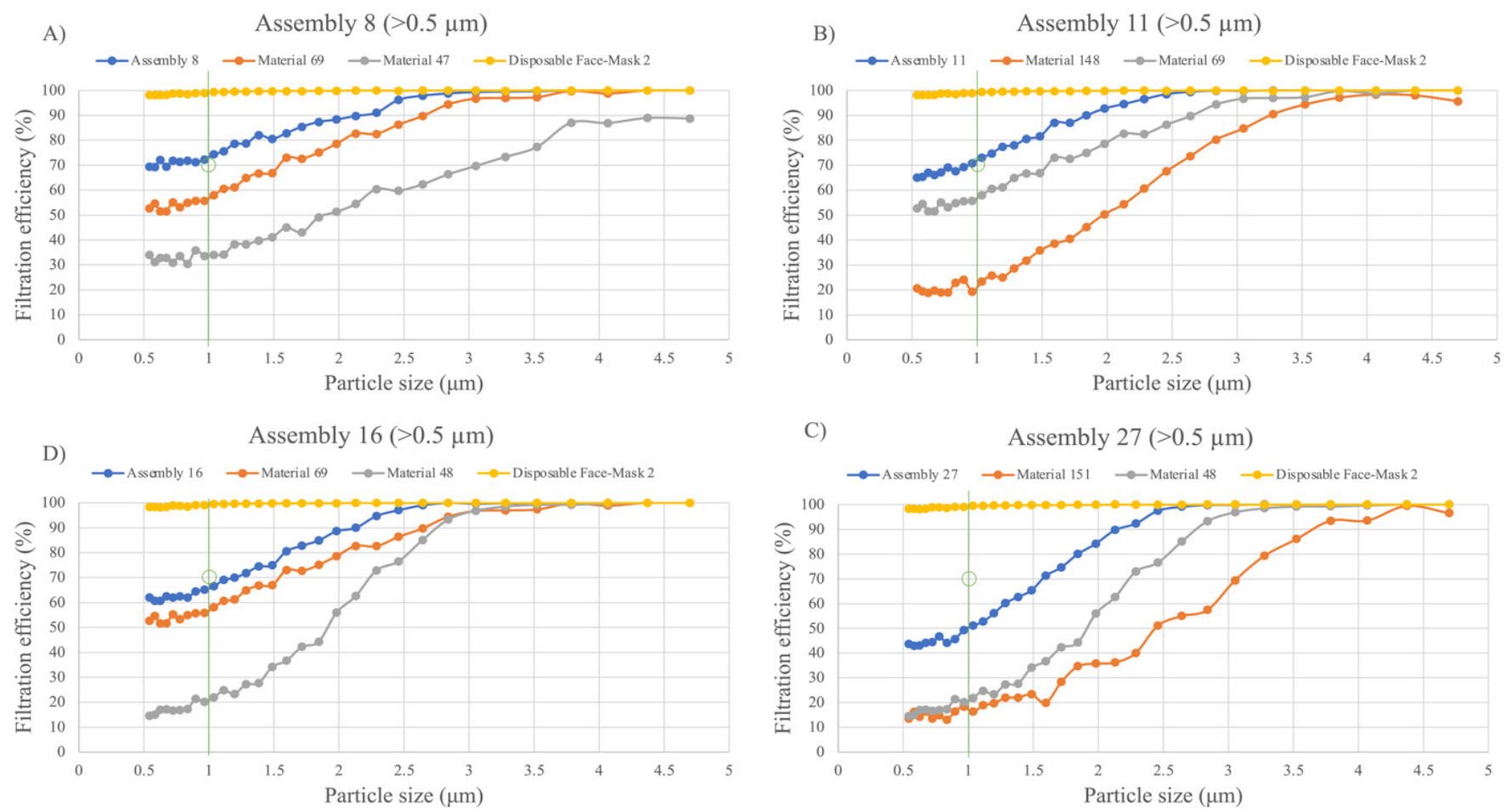

Fig. 7. Formation of assemblies. The green mark represents a filtration efficiency of $70 \%$ at $1.0 \mu \mathrm{m}$.
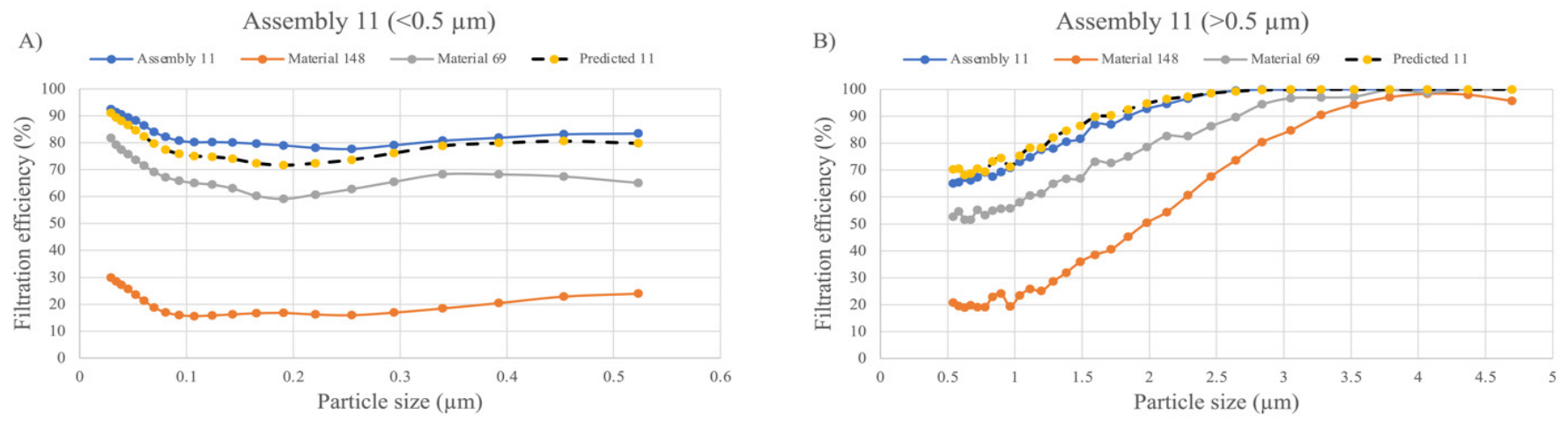

C)

Assembly $16(<0.5 \mu \mathrm{m})$
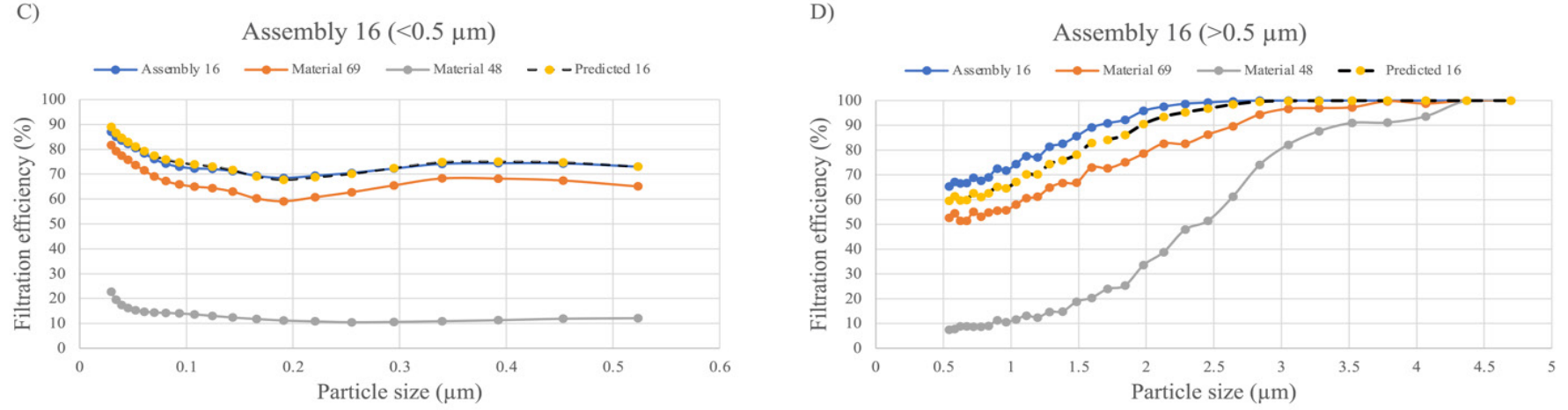

Fig. 8. Aerosol particle size-selective filtration efficiencies for individual measurements of materials that constitute the assemblies, together with the predicted fractional filtration efficiencies, for both particles size ranges: $(A, C)<0.5 \mu \mathrm{m}$ and $(B, D)>0.5 \mu \mathrm{m}$. 

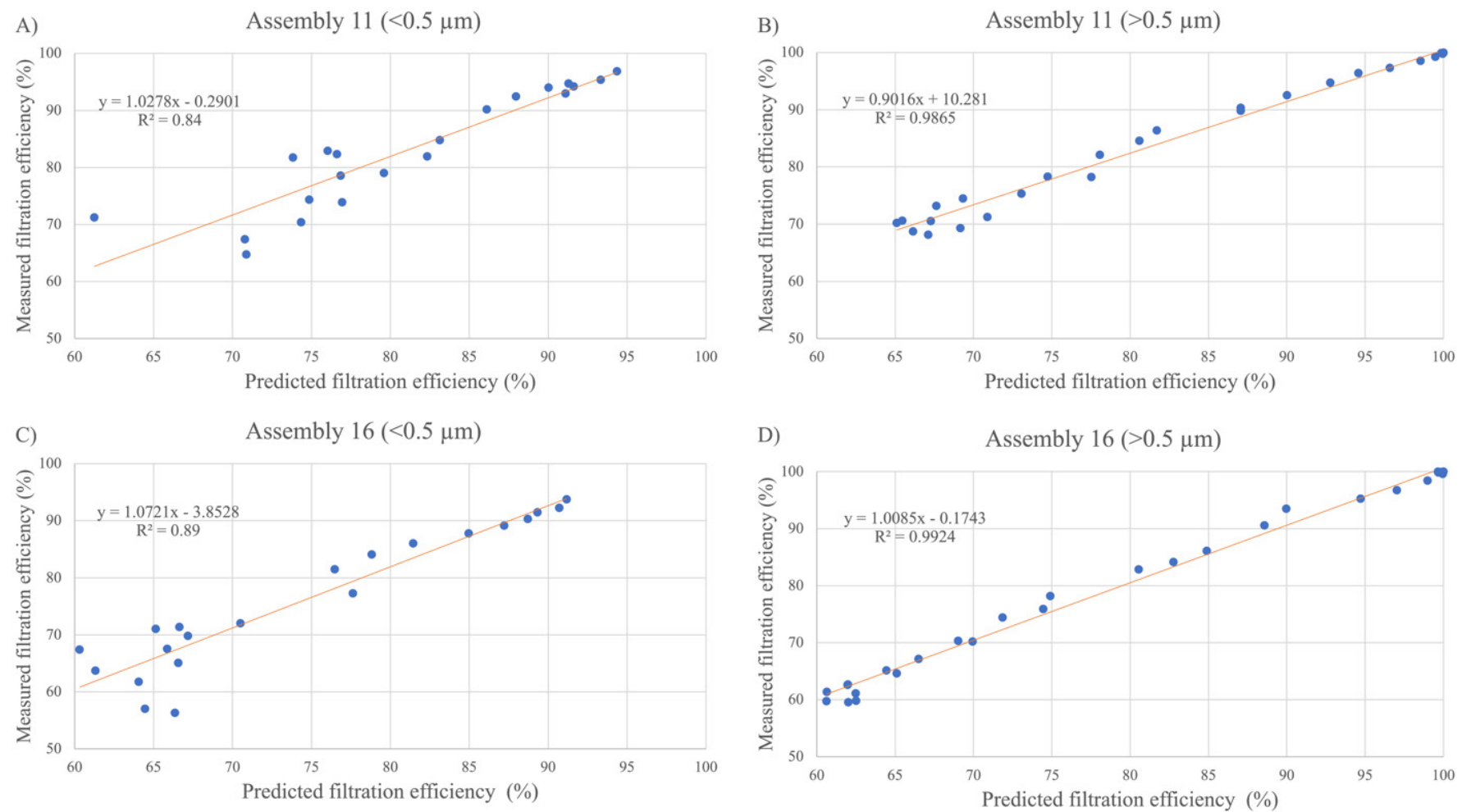

Fig. 9. Linear regression analysis for the measurements and predicted values of Assemblies 11 and 16.

A further analysis performed on seven assemblies, shown in Supplemental Material 6, yielded $\mathrm{R}^{2}$ values between 0.77 and 0.99 , pointing to the accuracy of the simple model in predicting the fractional filtration efficiencies of assemblies. It can be observed that the model tends to ensure higher accuracy for particles $>0.5 \mu \mathrm{m}$. It should be noted that this simple model can be used as a tool for predicting the performance of selected materials with individual known filtration efficiencies and pressure drops suitable for mask design as assemblies from layers.

\subsection{Coating, Hydrophobicity, and Filtration Efficiency}

The extended use of a face mask may result in accumulation of moisture, which further leads to a decrease in comfort and filtration efficiency (Mahdavi et al., 2015). Anticipating this challenge and attempting to prevent it, we coated a set of fabrics in accordance with the procedure described in the Materials and Methods section. By doing so, we were able to significantly increase the contact angle of water droplets, i.e., the hydrophobicity, as shown in Fig. 10(A). For a discussion on the correlation of TFE in the coated and non-coated samples, please see Supplemental Material 6.

Further, in Figs. 10(B) and 10(C), we show the average fractional filtration efficiencies over the ten aforementioned coated and non-coated fabrics separately for particles in the ranges $<0.5 \mu \mathrm{m}$ and $>0.5 \mu \mathrm{m}$. For both particle size ranges, the average fractional filtration efficiency of the coated materials is always greater than that of the non-coated ones. We note here an apparent minimum of around $0.25 \mu \mathrm{m}$ and a convergence of both measurements above $2.5 \mu \mathrm{m}$.

In Fig. 10(D), we show the fractional difference between the averages of the coated and noncoated materials. We clearly see that the coating has no effect on the MPPS range, where the filtration is at a minimum. Past the minimum, the fractional difference curve increases rapidly and peaks around the value of $1.0 \mu \mathrm{m}$ and then steadily decreases up to a particle size of $3.0 \mu \mathrm{m}$. Further experiments are needed to determine the mechanism at the base of this small change.

Although the effect of coating on filtration is small, to show that the change in filtration is correlated with the increase in hydrophobicity, we performed a two-sample t-test between the $\mathrm{TFE}^{\mathrm{C}}$ (of the coated samples) and increase in contact angle. We show a summary of this comparison in Table 1, and we note here that-although the effect is small - the $p$ values are 

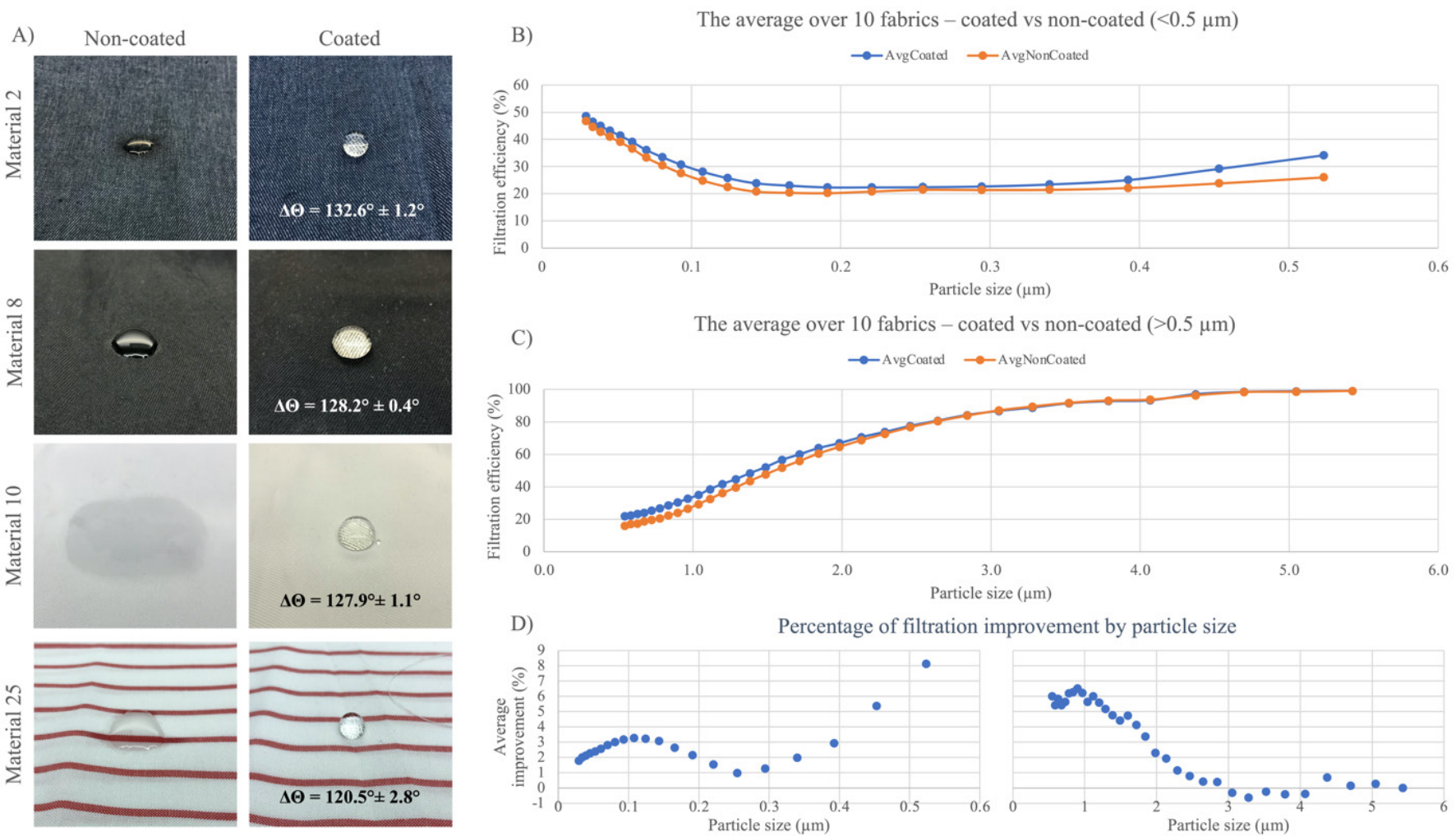

Fig. 10. Influence of coating on aerosol particle size-selective filtration performance. (A) Four materials before and after coating, with the increase in contact angle in overlay. $(B, C)$ Average filtration efficiency over 10 coated and non-coated fabrics for particles smaller and larger than $0.5 \mu \mathrm{m}$. (D) Percentage of filtration improvement per particle size.

Table 1. The correlation between the increase in the contact angle and total filtration efficiency (TFE) for coated fabrics.

\begin{tabular}{lll}
\hline Measurement and statistical test & & Value \\
\hline$\theta_{\text {contact }}$ Vs. $\left(\right.$ TFE $\left.^{\mathrm{C}}\right)<0.5 \mu \mathrm{m}$ & Pearson correlation & 0.6794 \\
& p-value & $3.37 \mathrm{E}-08$ \\
$\theta_{\text {contact }}$ Vs. $\left(\mathrm{TFE}^{\mathrm{C}}\right)>0.5 \mu \mathrm{m}$ & Pearson correlation & 0.4467 \\
& p-value & $1.33 \mathrm{E}-05$ \\
\hline
\end{tabular}

significant. This shows that, across a range of materials, the filtration efficiency is not negatively impacted by the coating, i.e., a hydrophobic treatment of the fabric will likely not decrease the filtration efficiency of the material. Given that the change in filtration efficiency for coated materials is small, we conclude that the potential change in pressure drop is also negligible.

\subsection{Reusable, Non-medical Face Masks Currently on the Market}

We investigated several non-medical, reusable face masks currently found on the market. To the best of our knowledge, with one exception (Western Europe 2), all these face masks have appeared in the context of the COVID-19 crisis. We either directly purchased these face masks or they were sent to us. We compared them against a generic, non-woven disposable face mask distributed in Switzerland and widely available in local supermarkets.

Overall, the filtration efficiencies of these reusable face masks proved to be rather low. With one exception, the fractional filtration efficiency is, in the best case, at around $50 \%$ at a $1.0-\mu \mathrm{m}$ particle size diameter. However, the exception (the Southern Asia 1 product) has an incredibly high pressure drop, i.e., very low breathability, which renders its filtration properties useless (see Fig. 11). We note that, although several of these products came from countries where the governments have elaborated norms for reusable face masks, we observed generally poor 

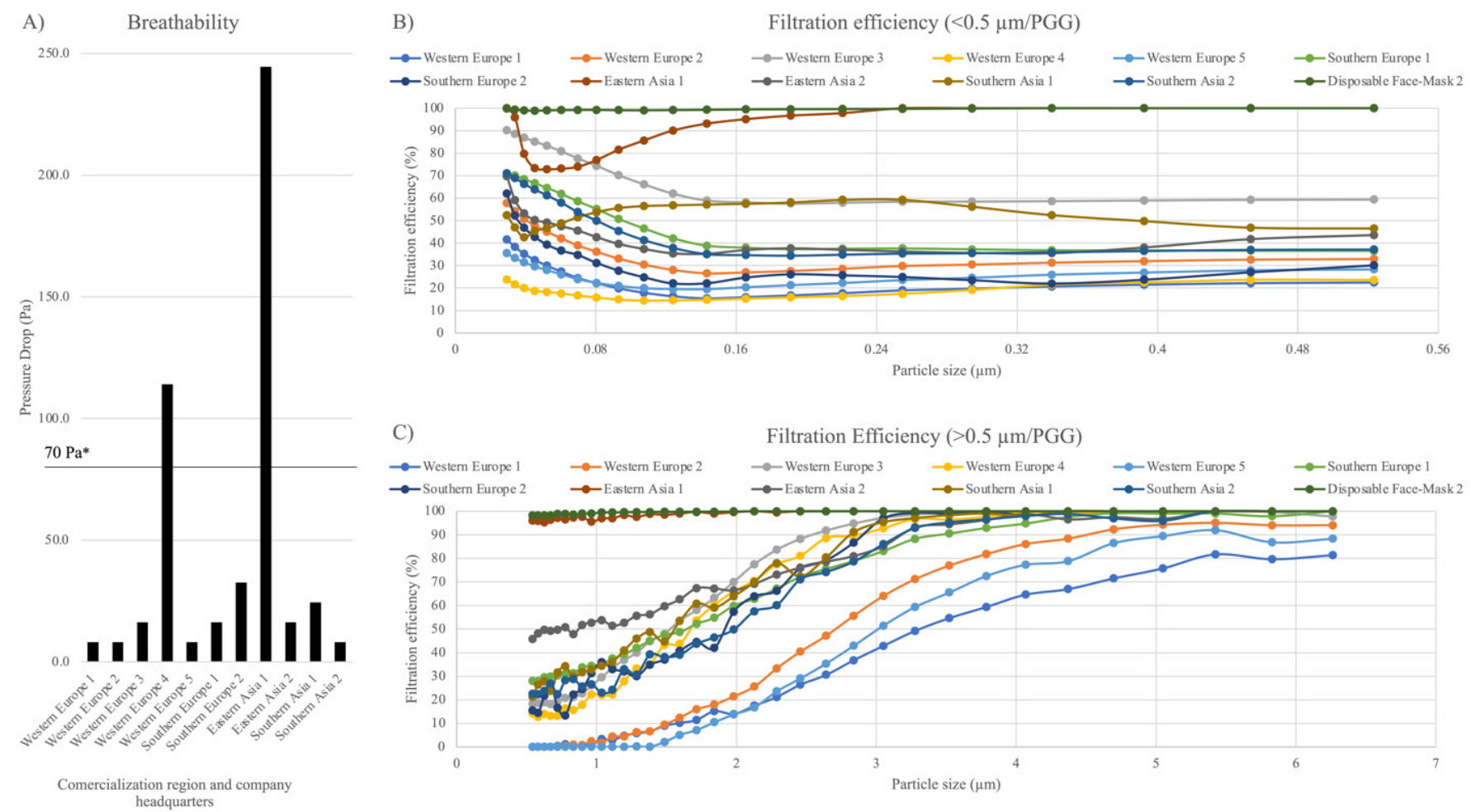

Fig. 11. (A) Breathability and (B, C) particle size-selective filtration efficiencies in two particle size ranges, i.e., $<0.5 \mu \mathrm{m}$ and $>0.5 \mu \mathrm{m}$, respectively, of various commercial, reusable face masks from different regions of the globe. *indicates the level of breathability of the Type IIR surgical face mask or that required by the Swiss Standards for Community Masks (see Supplemental Material 3).

performance of these masks from the perspective of filtration efficiency. This gives significant room for improvement to be considered in this research area for future mask designs.

\section{CONCLUSIONS}

Starting from the results provided by the semi-automated text-mining platform Taxila ${ }^{\mathrm{TM}}$, we established a workflow for screening and analyzing various fabrics and assemblies of fabrics from which reusable face masks can be fabricated. We focused on determining two essential physical parameters that define the performance of face masks, i.e., the pressure drop across the fabric (breathability) and fractional aerosol particle size-selective filtration efficiency. We also showed that, for assemblies, the latter can be predicted from the measurements of single fabrics, potentially reducing the time and effort needed for supplemental screening and accurate measurements.

Our objective was to set up a workflow that would allow the identification of fabrics that perform well in filtration and breathability and that can be used in reusable face masks. We keep away from providing any sorted list of materials and assemblies, as any such list would be arbitraryprovided the differences between guidelines and norms elaborated by national governments and regional regulatory bodies.

While a discussion on the fit of the mask to the facial traits is more than warranted in this context, our workflow was designed to assess only the physical properties of the materials of the reusable mask. Considerations pertaining to the design choice or adaptability to facial traits are beyond the scope of this work. However, in case of an imperfect fit, it is worth mentioning that while the large particles will remain more likely to be removed by impaction, the smaller particles will more readily follow the current lines through the gaps between the skin and the mask. This basic phenomenon will decrease the effective filtration efficiency of any reusable or disposable face mask.

Our measurements on the filtration efficiency of (non-)woven fabrics revealed the importance of neutralizing the aerosol when the precise determination of the filtration properties for small 
particles is needed. Indeed, for certain regional recommendations for reusable face masks, like those employed in Switzerland, for example, the difference in filtration efficiency at $1.0 \mathrm{~mm}$ might impact the result. However, to the best of our knowledge, most regional and national criteria employ filtration efficiency measurements at $3.0 \mathrm{~mm}$, where the difference between using a neutralized and a non-neutralized aerosol are well within the error bars of the measurement.

In addition to aerosol filtration and breathability, additional practical, biochemical, and toxicological considerations can be applied to the materials used for making face masks. For example, the biocompatibility of the materials is an important factor for face masks that come into contact with the skin for prolonged periods of time (Matusiak et al., 2020). Antiviral coating of the surface of the mask can be considered, so that the risk of contamination upon touching the mask is reduced. The bioburden, related to microorganisms present in the filter material, is another important concern (Luksamijarulkul et al., 2014; Majchrzycka et al., 2016). Finally, because of extended use and mechanical stress, the potential release of fibers from the filtration material is an important consideration for face masks, owing to their proximity to the respiratory tract. For example, materials such as fleece-sometimes mentioned as an intermediate layer in DIY face masks (CHU Grenoble, 2020) - release a large number of microfibers during washing and undergoes mechanical deformation (De Falco et al., 2018). Hence, whilst being out of the scope of the current work, the workflow employed here can be extended to include analyses of biocompatibility, bioburden, and fiber release of the most promising assemblies identified. Finally, for the finalized fabricated face masks, it would be beneficial to be assess how the filtration properties and breathability are impacted by accumulation of moisture.

We have demonstrated that biodegradable fabrics can be layered together to create face masks that meet very demanding criteria. The solid workflow developed herein provides opportunities for a sustainable and environmentally friendly solution in the context of the COVID-19 crisis.

\section{ACKNOWLEDGEMENTS}

The authors would like to thank Dr. Chris Wyss from XpertTox for his valuable insights on regulatory strategy and testing paradigm.

\section{DISCLAIMER}

This work has received funding and support from Philip Morris International, CQ Corporate Fashion $\mathrm{GmbH}$, INVENesis Sàrl, and Coat-X SA. The project, under the name ProMask.CH consortium, was co-funded by the Canton of Bern, Switzerland, from the Corona emergency loans designed to support the local economy during the COVID-19 crisis. The authors A.S., S.S., S.M., S.S.W., T.Z.S., P.A.G., S.L., A.K., M.P., and J.H. are employees of Philip Morris International. The authors J.S., Y.T., and A.H., are employees of Coat-X SA, while J.-L.P. is employed by INVENesis Sàrl. S.Q. is an employee of CQ Corporate Fashion $\mathrm{GmbH}$.

\section{SUPPLEMENTARY MATERIAL}

Supplementary material for this article can be found in the online version at https://doi. org/10.4209/aaqr.210052

\section{REFERENCES}

Abaluck, J., Chevalier, J.A., Christakis, N.A., Forman, H.P., Kaplan, E.H., Ko, A., Vermund, S.H. (2020). The case for universal cloth mask adoption \& policies to increase the supply of medical masks for health workers (SSRN Scholarly Paper No. ID 3567438). Social Science Research Network, Rochester, NY. https://doi.org/10.2139/ssrn.3567438

BBC News (2020). Coronavirus: WHO rethinking how covid-19 spreads in air. https://ww w.bbc.com/news/world-53329946 (accessed 13 July 2020). 
Bourouiba, L., Dehandschoewercker, E., Bush, J.W.M. (2014). Violent expiratory events: On coughing and sneezing. J. Fluid Mech. 745, 537-563. https://doi.org/10.1017/jfm.2014.88

Bourouiba, L. (2020). Turbulent gas clouds and respiratory pathogen emissions: Potential implications for reducing transmission of COVID-19. JAMA 323, 1837-1838. https://doi.org/10. 1001/jama.2020.4756

Brienen, N.C.J., Timen, A., Wallinga, J., Van Steenbergen, J.E., Teunis, P.F.M. (2010). The effect of mask use on the spread of influenza during a pandemic. Risk Anal. 30, 1201-1218. https://doi.org/10.1111/j.1539-6924.2010.01428.x

Center for Disease Control and Prevention (CDC) (2020). Use of cloth face coverings to help slow the spread of COVID-19. https://www.cdc.gov/coronavirus/2019-ncov/prevent-getting-sick/diycloth-face-coverings.html (accessed 23 May 2020).

CHU Grenoble (2020). Mask tutorial. https://www.hospitalia.fr/attachment/1878139/ (accessed 13 March 2020).

Clase, C.M., Fu, E.L., Joseph, M., Beale, R.C.L., Dolovitch, M.B., Jardine, M., Mann, J.F.E., PecoitsFiho, R., Winkelmayer, W.C., Carrero, J.J. (2020). Cloth masks may prevent transmission of COVID-19: An evidence-based, risk-based approach. Ann. Intern. Med. 173, 489-491. https://doi.org/10.7326/M20-2567

Davies, A., Thompson, K.-A., Giri, K., Kafatos, G., Walker, J., Bennett, A. (2013). Testing the efficacy of homemade masks: Would they protect in an influenza pandemic? Disaster Med. Public Health Prep. 7, 413-418. https://doi.org/10.1017/dmp.2013.43

De Falco, F., Gullo, M.P., Gentile, G., Di pace, E., Cocca, M., Gelabert, L., Brouta-Agnésa, M., Rovira, A., Escudero, R., Villalba, R., Mossotti, R., Montarsolo, A., Gavignano, S., Tonin, C., Avella, M. (2018). Evaluation of microplastic release caused by textile washing processes of synthetic fabrics. Environ. Pollut. 236, 916-925. https://doi.org/10.1016/j.envpol.2017.10.057

Direction Générale de l'Armement (DGA) (2020). L'expertise technique du ministère des armées au service de la lutte contre le Covid-19. https://www.defense.gouv.fr/english/dga/actualite/lexpertise-technique-du-ministere-des-armees-au-service-de-la-lutte-contre-le-covid-19 (accessed 15 May 2020).

Eikenberry, S.E., Mancuso, M., Iboi, E., Phan, T., Eikenberry, K., Kuang, Y., Kostelich, E., Gumel, A.B. (2020). To mask or not to mask: Modeling the potential for face mask use by the general public to curtail the COVID-19 pandemic. Infect. Dis. Model. 5, 293-308. https://doi.org/10.10 16/j.idm.2020.04.001

European Center for Disease Prevention and Control (ECDC) (2020). Technical report: Using face masks in the community: Reducing COVID-19 transmission from potentially asymptomatic or pre-symptomatic people through the use of face masks. https://www.ecdc.europa.eu/sites/d efault/files/documents/COVID-19-use-face-masks-community.pdf (accessed 4 June 2020).

European Comittee for Standardization (2009). Cen: Norm en149:2001 + a1:2009: Respiratory protective devices - filtering half masks to protect against particles - requirements, testing, marking. https://standards.cen.eu/dyn/www/f?p=204:110:0::::FSP_PROJECT,FSP_ORG_ID:32 928,6062\&cs=1FC98AD34A5EE26A0CB5A6155ED4D6E5E (accessed 13 July 2020).

European Comittee for Standardization (2019). Cen: Norm en14683:2019 + ac:2019: Medical face masks - requirements and test methods. https://standards.cen.eu/dyn/www/f?p=204:110:0:: ::FSP_PROJECT:69675\&cs=1956C06A1BAF887FF462DD56057D34F29 (accessed 13 July 2020).

Fadare, O.O., Okoffo, E.D. (2020). Covid-19 face masks: A potential source of microplastic fibers in the environment. Sci. Total Environ. 737, 140279. https://doi.org/10.1016/j.scitotenv.2020. 140279

Federal Office of Public Health (2020). New coronavirus: Masks. https://www.bag.admin. ch/bag/en/home/krankheiten/ausbrueche-epidemien-pandemien/aktuelle-ausbrueche-epid emien/novel-cov/masken.html\#1189346292 (accessed 3 August 2020).

Greenhalgh, T., Schmid, M.B., Czypionka, T., Bassler, D., Gruer, L. (2020). Face masks for the public during the covid-19 crisis. BMJ 369, m1435. https://doi.org/10.1136/bmj.m1435

Han, Z.Y., Weng, W.G., Huang, Q.Y. (2013). Characterizations of particle size distribution of the droplets exhaled by sneeze. J. R. Soc. Interface 10, 20130560. https://doi.org/10.1098/rsif.201 3.0560

Hinds, W.C. (1999). Aerosol technology: Properties, behavior, and measurement of airborne particles, 2nd ed. John Wiley, Chichester. 
Ho, K.F., Lin, L.., Weng, S.P., Chuang, K.J. (2020). Medical mask versus cotton mask for preventing respiratory droplet transmission in micro environments. Sci. Total Environ. 375, 139510. https://doi.org/10.1016/j.scitotenv.2020.139510

Hogg, A., Aelen, T., Uhl, S., Graf, B., Keppner, H., Tardy, Y., Burger, J. (2013). Ultra-thin layer packaging for implantable electronic devices. J. Micromech. Microeng. 23, 075001. https://doi.org/10.1088/0960-1317/23/7/075001

International Organization for Standardization (2004). ISO 22609:2004: Clothing for protection against infectious agents - medical face masks - test method for resistance against penetration by synthetic blood (fixed volume, horizontally projected). https://www.iso.org/sta ndard/35055.html (accessed 13 July 2020).

Iskandar, A., Gonzalez-Suarez, I., Majeed, S., Marescotti, D., Sewer, A., Xiang, Y., Leroy, P., Guedj, E., Mathis, C., Schaller, J.S., Vanscheeuwijck, P., Frentzel, S., Martin, F., Ivanov, N.I., Peitsch, M., Hoeng, J. (2016). A framework for in vitro systems toxicology assessment of e-liquids. Toxicol. Mech. Meth. 26, 392-416. https://doi.org/10.3109/15376516.2016.1170251

Jayaweera, M., Perera, H., Gunawardana, B., Manatunge, J. (2020). Transmission of COVID-19 virus by droplets and aerosols: A critical review on the unresolved dichotomy. Environ. Res. 188, 109819. https://doi.org/10.1016/j.envres.2020.109819

Kim, J.M., Chung, Y.S., Jo, H.J., Lee, N.J., Kim, M.S., Woo, S.H., Park, S., Kim, J.W., Kim, H.M., Han, M.G. (2020). Identification of coronavirus isolated from a patient in Korea with COVID-19. Osong Public Health Res. Prespect. 11, 3-7. https://doi.org/10.24171/j.phrp.2020.11.1.02

Konda, A., Prakash, A., Moss, G.A., Schmoldt, M., Grant, G., Guha, S. (2020). Aerosol filtration efficiency of common fabrics used in respiratory cloth masks. ACS Nano 14: 6339-6347. https://doi.org/10.1021/acsnano.0c03252

Leung, N.H.L., Chu, D.K.W., Shiu, E.Y.C., Chan, K.H., McDewitt, J.J., Hau, B.J.P., Yen, H.L., Li, Y., Ip, D.K.M., Peiris, J.S.M., Seto, W.H., Leung, G.M., Milton, D.K., Cowling, B.J. (2020). Respiratory virus shedding in exhaled breath and efficacy of face masks. Nat. Med. 26, 676-680. https://doi.org/10.1038/s41591-020-0843-2

Long, Y., Hu, T., Liu, L., Chen, R., Guo, Q., Yang, L., Cheng, Y., Huang, J., Du, L. (2020). Effectiveness of n95 respirators versus surgical masks against influenza: A systematic review and metaanalysis. J. Evid. Based Med. 13, 93-101. https://doi.org/10.1111/jebm.12381

Luksamijarulkul, P., Aiempradit, N., Vatanasomboon, P. (2014). Microbial contamination on used surgical masks among hospital personnel and microbial air quality in their working wards: A hospital in bangkok. Oman Med. J. 29, 346-350. https://doi.org/10.5001/omj.2014.92

Lustig, S.R., Biswakarma, J.J.H., Rana, D., Tilford, S.H., Hu, W., Su, M., Rosenblatt, M.S. (2020). Effectiveness of common fabrics to block aqueous aerosols of virus-like nanoparticles. ACS Nano Article ASAP. https://pubs.acs.org/action/showCitFormats?doi=10.1021/acsnano.0c039 $72 \&$ ref $=p d f$

Macintyre, C.R., Seale, H., Dung, T.C., Hien, N.T., Nga, P.T., Chughtai, A.A., Rahman, B., Dwyer, D.E., Wang, Q. (2015). A cluster randomised trial of cloth masks compared with medical masks in healthcare workers. BMJ Open 5, e006577. https://doi.org/10.1136/bmjopen-2014-006577

Macintyre, R.C., Hasanain, S.J. (2020). Community universal face mask use during the COVID 19 pandemic-from households to travellers and public spaces. J. Travel Med. 27, taaa056. https://doi.org/10.1093/jtm/taaa056

Mahdavi, A., Haghighat, F., Bahloul, A., Brochot, C., Ostiguy, C. (2015). Particle loading time and humidity effects on the efficiency of an N95 filtering facepiece respirator model under constant and inhalation cyclic flows. Ann. Occup. Hyg. 59, 629-640. https://doi.org/10.1093/annhyg/mev005

Majchrzycka, K., Okrasa, M., Skora, J., Gutarowska, B. (2016). Evaluation of the survivability of microorganisms deposited on filtering respiratory protective devices under varying conditions of humidity. Int. J. Environ. Res. Public Health 13, 98. https://doi.org/10.3390/ijerph13010098

Morawska, L., Johnson, G., Ristovski, Z., Hargreaves, M., Mengersen, K., Corbett, S., Chao, C., Li, Y., Katoshevski, D. (2009). Size distribution and sites of origin of droplets expelled during expiratory activities. J. Aerosol Sci. 40, 256-269. https://doi.org/10.1016/j.jaerosci.2008.11.002

Matusiak, L., Szepietowska, M., Krajewski, P., Bialynicki-Birula, R., Szepietowski, J.C. (2020). Inconveniences due to the use of face masks during the COVID-19 pandemic: A survey study of 876 young people. Dermatol. Ther. 33, e13567. https://doi.org/10.1111/dth.13567

National Institute for Occupational Safety and Health (NIOSH) (1996). NIOSH guide to the selection 
and use of particulate respirators. https://www.cdc.gov/niosh/docs/96-101/default.html (accessed 13 July 2020).

Pleil, J.D., Breauchamp, J.D., Risby, T.H., Dweik, R.A. (2020). The scientific rationale for the use of simple masks or improvised facial coverings to trap exhaled aerosols and possibly reduce the breathborne spread of COVID-19. J. Breath Res. 14, 030201. https://doi.org/10.1088/17527163/ab8a55

Prata, J.C., Silva, A.L.P., Walker, T.R., Duarte, A.C., Rocha-Santos, T. (2020). COVID-19 pandemic repercussions on the use and management of plastics. Environ. Sci. Technol. 13, 7760-7765. https://doi.org/10.1021/acs.est.0c02178

Rengasamy, S., Eimer, B., Shaffer, R. (2010). Simple respiratory protection-evaluation of the filtration performance of cloth masks and common fabric materials against $20-1000 \mathrm{~nm}$ size particles. Ann. Occup. Hyg. 54, 789-798. https://doi.org/10.1093/annhyg/meq044

Safe Communities Portugal (2020). Guidance on the use of masks by the general population. Issued by the director general of health. https://www.ecdc.europa.eu/sites/default/files/doc uments/COVID-19-use-face-masks-community.pdf (accessed 4 June 2020).

Schmidt, E. (2008). Dust Separation, in: Ullmann's Encyclopedia of Industrial Chemistry, American Cancer Society. https://doi.org/10.1002/14356007.b02_13.pub2

Stalder, A.F., Kulik, G., Sage, D., Barbieri, L., Hoffmann, P. (2006). A snake-based approach to accurate determination of both contact points and contact angles. Colloids Surf., A 286, 92103. https://doi.org/10.1016/j.colsurfa.2006.03.008

Stutt, R.O.J.H., Retkute, R., Bradley, M., Gilligan, C.A., Colvin, J. (2020). A modelling framework to assess the likely effectiveness of facemasks in combination with 'lock-down' in managing the COVID-19 pandemic. Proc. R. Soc. London, Ser. A 476, 20200376. https://doi.org/10.1098/rsp a.2020.0376

Sunjaya, A.P., Jenkins, C. (2020). Rationale for universal face masks in public against COVID-19. Respirology 25, 678-679. https://doi.org/10.1111/resp.13834

Swiss National COVID-19 Science Task Force (NCS-TF) (2020). Recommendations for minimal specifications for the community masks for swiss manufacturers. https://www.empa.ch/docu ments/12524755/0/22.04.2020+Community+mask+spec+and+recommendations+for+minim al+values+V4-final.pdf/8aa76f3c-428c-46e2-b9c3-4d4af29716f2 (accessed 22 May 2020).

Tang, J.W., Nicolle, A.D., Klettner, C.A., Pantelic, J., Wang, L., Suhaimi, A.B., Tan, A.Y., Ong, G.W., Su, R., Sekhar, C., Cheong, D.D., Tham, K.W. (2013). Airflow dynamics of human jets: Sneezing and breathing - potential sources of infectious aerosols. PLoS One 8, e59970. https://doi.org/ 10.1371/journal.pone.0059970

The New York Times (2020). 239 experts with one big claim: The coronavirus is airborne. https://www.nytimes.com/2020/07/04/health/239-experts-with-one-big-claim-the-coronaviru s-is-airborne.html (accessed 13 Jul 2020).

Thomas, D., Charvet, A., Bardin-Monnier, N., Appert-Collins, J.C. (2016). Aerosol filtration. ISTE Press - Elsevier.

Tracht, S.M., Del Valle, S.Y., Hyman, J.M. (2010). Mathematical modeling of the effectiveness of facemasks in reducing the spread of novel influenza A (H1N1). PLoS One 5, e9018. https://doi.org/10.1371/journal.pone.0009018

van der Sande, M., Teunis, P., Sabel, R. (2008). Professional and home-made face masks reduce exposure to respiratory infections among the general population. PLoS One 3, e2618. https://doi.org/10.1371/journal.pone.0002618

Wikipedia (2021). Face masks during the COVID-19 pandemic. https://en.wikipedia.org/wi ki/Face_masks_during_the_COVID-19_pandemic (accessed 10 May 2021).

World Economic Forum (2020). Corona virus: Here are 4 ways to make your own facemask. https://www.weforum.org/agenda/2020/05/face-mask-diy-health-pandemic (accessed 4 May 2020).

World Health Organisation (WHO) (2020). Advice on the use of masks in the context of COVID-19: Interim guidance. World Health Organization. https://apps.who.int/iris/handle/10665/331693

Wu, H., Huang, J., Zhang, C.J.P., He, Z., Ming, W.K. (2020). Facemask shortage and the novel coronavirus disease (COVID-19) outbreak: Reflections on public health measures. EClinicalMedicine 21. https://doi.org/10.1016/j.eclinm.2020.100329

Zhao, M., Liao, L., Xiao, W., Yu, X., Wang, Q., Lin, Y.L., Kilinc-Balci, F.S., Price, A., Chu, L., Chu, M.C., 
Chu, S., Cui, Y. (2020). Household materials selection for homemade cloth face coverings and their filtration efficiency enhancement with triboelectric charging. Nano Lett. 20, 5544-5552. https://doi.org/10.1021/acs.nanolett.0c02211 